Asian Journal of Computer Science and Technology

ISSN: 2249-0701 Vol.7 No.S1, 2018, pp. 54-57

(C) The Research Publication, www.trp.org.in

\title{
IoT Enabled Soil Testing
}

\author{
P. Sindhu ${ }^{1}$ and G. Indirani ${ }^{2}$ \\ ${ }^{1 \& 2}$ Assistant Professor, \\ ${ }^{1}$ Department of Computer Science, Mahatma Gandhi Government Arts College, Mahe, Maharashtra, India \\ ${ }^{2}$ Department of Computer Science \& Engineering, Annamalai University, Annamalai Nagar, Tamil Nadu, India \\ E-Mail: psindumano@gmail.com, induk0992@gmail.com
}

\begin{abstract}
Agriculture is the main occupation of our country and it plays a vital role in our country. Using too much of fertilizers may lead to the inferior quality of the crop production. So the measurement of soil nutrients is greatly required for better plant growth. Determining the amount of nutrients in the soil is the key function. $\mathrm{pH}$ value is also one of the most important and informative soil parameter to detect the soil fertility and it is measured to identify the soil fertility. In the proposed system, it determines the crops which are suitable for the particular soil type. It will analyze moisture content, temperature and humidity in soil at real time and it will also suggest the crops based on determined $\mathrm{PH}$ of soil. This system is proposed to help the farmers to increase the production and the suggestions are made through the mobile application.
\end{abstract}

Keywords: Internet of Things, Soil Testing

\section{INTRODUCTION}

Watering fields; cultivating crops with required fertilizers etc. are the farming activities involved in conventional farming. These practices are performed manually. [1] Crop production mainly depends on the soil and properties of plant interaction. The farmer uses this as a valuable tool. This determines the soil fertility for better and economical crop production. Soil test helps to decide the nature of the soil whether it is acid or base and which crops will give maximum productivity. Depending upon the minerals available in the soil, we can estimate the plant rate of nutrients absorption. There is degradation in the production of crops because of insufficient rate of nutrients. Macro nutrients are the major requirement of the nutrients necessary for plant growth. Correct usage of fertilizer is required for better growth. Over usage of fertilizer leads to the reduction in harvest production rate. Manual fertilization is still followed in some parts of India. This type of manual fertilization makes the soil condition error prone. The demand of food production is increasing rapidly. The quantity will be decided depending on the type of crop and] growth of plants. The farmers measure the nutrients concentration present in the soil to get the soil nutrients to be provided and select the suitable crop for multiple times of cropping in the farmland.

\section{THE EXISTING SYSTEM}

Soil testing refers to the chemical analysis of soils and is well recognized as a scientific means for quick characterization of the fertility status of soils and predicting the nutrient requirement of crops. It also includes testing of soils for other properties like texture, structure, $\mathrm{pH}$, Cation Exchange Capacity, water holding capacity, electrical conductivity and parameters for amelioration of chemically deteriorated soils for recommending soil amendments, such as gypsum for alkali soil and lime for acid soil. There are mainly two types of soil testing methods.

A. Soil testing in laboratory

B. Mobile soil testing

\section{A. Soil Testing In Laboratory}

This method involves soil testing in laboratory. It may take weeks or days to test the soil. The people take soil samples and give them to the laboratories for soil testing. [2] They detect the NPK values of soil by using chemical analysis.

\section{B. Mobile Soil Testing}

In this type people do the test and give suggestions on the tests regarding, the fertilizers and it is done once per crop. So this method is not suitable for effective crop production and it does not give the accurate results. The following three methods are used for detecting the soil fertility. They are
1. Spectroscopy
2. Conductivity and
3. Electro chemical sensor methods.

These are cost effective and will not give the accurate results. [3]

\section{PROPOSED SYSTEM}

The main component of this system is microcontroller. The Node MCU with ESP8266 Wi-Fi shield is the micro controller, sensors like temperature, soil moisture and light intensity are used for the proposed system. The system is cost effective and easy to handle. The data is collected from sensors and it is uploaded to server and by using data the graph is drawn. We can make use of this system in multiple purposes by connecting different devices like, water pump and we can control it by using our mobile phone with internet connectivity.

The microcontroller used for this system is Node MCU 1.0 (ESP826612E) WiFi module and the various types of 
sensors

1. Soil moisture sensor

2. PH Meter

3. Humidity Sensor.

The system is low power consuming and easy to operate. The data is monitored with accurate date and time. The system is designed in such a way that we can communicate with our proposed system in real time and give suggestions to the farmers at any time.

\section{A. Node MCU 1.0 (ESP8266 12E WiFi module)}

It is an integrated version of the popular Esp8266 WiFi system on a chip that operates first on a system. The Esp8266 EX is integrated with a 32-bit Tensilica processor standard digital peripheral interface, antenna, switches, RF balun, power amplifiers, filters and power management modules. It achieves extra low power consumption and reaches a clock speed of 160MHZ. It has power saving architecture with three modes of operation, sleep mode, active mode and deep sleep mode. The real time operating system (RTOS) and WiFi stack about $80 \%$ of the processing power to be available for user application programming and development.

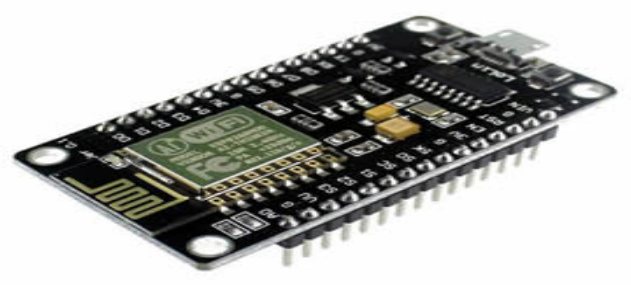

Fig. 1 Node MCU 1.0(ESP8266 12-E wiFi)

B. Soil Moisture Sensor-YL-38 + YL-69

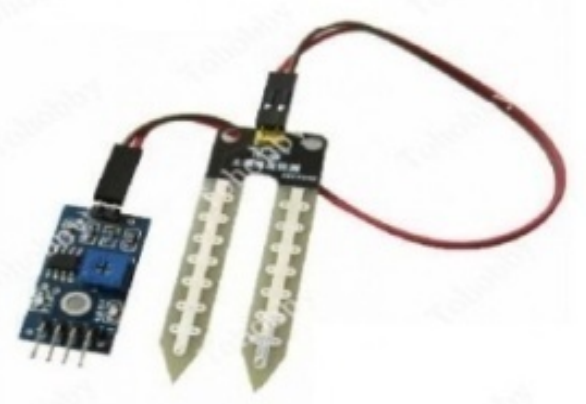

Fig. 2 Soil Moisture Sensor

The soil moisture sensor measure the volumetric water content indirectly by using some other property of the soil such as electrical resistance, dielectric or indirect with neutrons as a proxy for the moisture content. This sensor can be used to test the moisture of soil, when the soil is having water shortage; the module output is at high level otherwise the output is at low level. By using this sensor one can automatically water the flower plant, or any other plants requiring automatic watering technique. Module has triple output mode, digital output is simple, analog output is more accurate and serial output with exact readings [11].

\section{Soil pH Meter}

It is 2 in $1 \mathrm{pH}$ Meter for soil. It will give Soil Moisture and $\mathrm{pH}$ of the soil. Two in one $\mathrm{pH}$ meter and soil tester is a perfect tool for every farmer and gardener. This handy tool facilitates easy reading of the $\mathrm{pH}$ of the soil as well as its moisture content. This tool depicts a clear outline when to water the soil and keep the water content optimal which is essential for its healthy plant growth, The main characteristic of this tool is that it can be used to measure the $\mathrm{pH}$ of the soil. Different plants require different $\mathrm{pH}$ for their fast and healthy growth. This tool analyses $\mathrm{pH}$ and helps you to provide fertilizers as required.

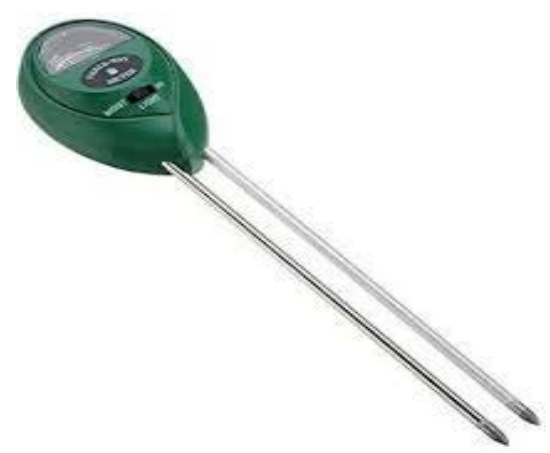

Fig. 3 Soil pH Meter

\section{Temperature and Humidity Sensor - DHT11}

The DHT11 is an ultra-low-cost and basic digital temperature and humidity sensor. It uses a thermistor to measure the surrounding air, a capacitive humidity sensor and spits out a digital signal (no need of analog input pinspin. This sensor is simple to use, but requires some time to grab the data. The only downside of the DHT11 sensor is for every 2 seconds only we can get new data from it, shown we using the libraries, readings of sensor can be up to 2 seconds old. [9].

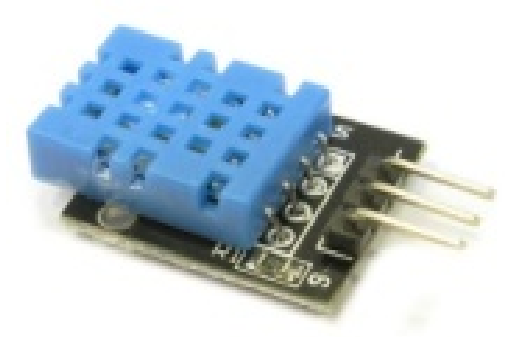

Fig. 4 DHT11 Sensor 


\section{ARCHITECTURE OF THE PROPOSEDSYSTEM}

\section{A. Architecture of the System}

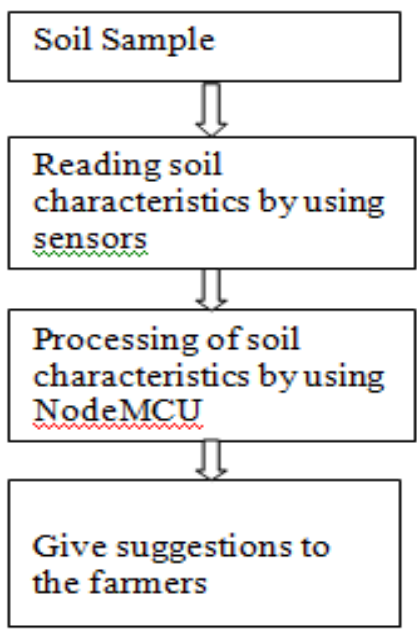

Fig. 5 Architecture of the system

\section{B. Block Diagram of the System}

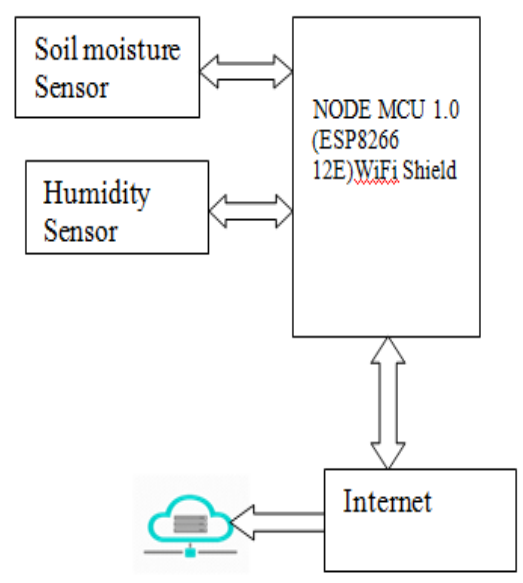

Fig. 6 Block Diagram

\section{Connection diagram}

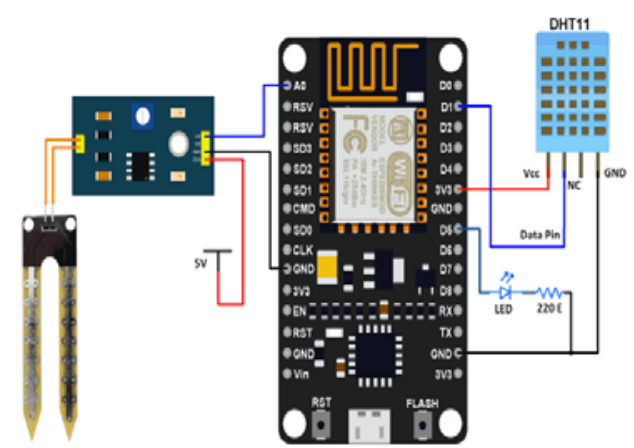

Fig. 7 Connection diagram

\section{Working Principle}

The system consists of pH Meter, Humidity Sensor, Soil moisture sensor, Node MCU (Esp8266) WiFi shield. In this system the $\mathrm{pH}$ Meter measures the $\mathrm{pH}$ value of the soil and soil moisture level and if the $\mathrm{pH}$ value is below 7 acidic and above 7 is basic and value is 7 means neutral and it is ideal for many plant Based on the $\mathrm{pH}$ value we can give instruction to the farmers which vegetable can give high productivity in that particular soil. The data read from sensor is send to the IoT Cloud Server (Thingspeak.com). In this cloud server we can create a channel either publicly or privately on which data can be displayed with correct time and date. A Temperature, Humidity, soil moisture level graph can be drawn here. Arduino IDE is used for writing the entire code. [7]

\section{RESULTS AND ANALYSIS}

The IoT enabled Soil Testing system, $\mathrm{pH}$ value and soil moisture of soil is reliable and capable for monitoring agricultural parameters. The output can be viewed in serial monitor of the Arduino IDE as well as login to Thingspeak.com Cloudserver. The graphs plotted in Thing speak server is shown in the below given fig.8, fig. 9, fig. 10 and fig. 11 shows the prototype of the system.

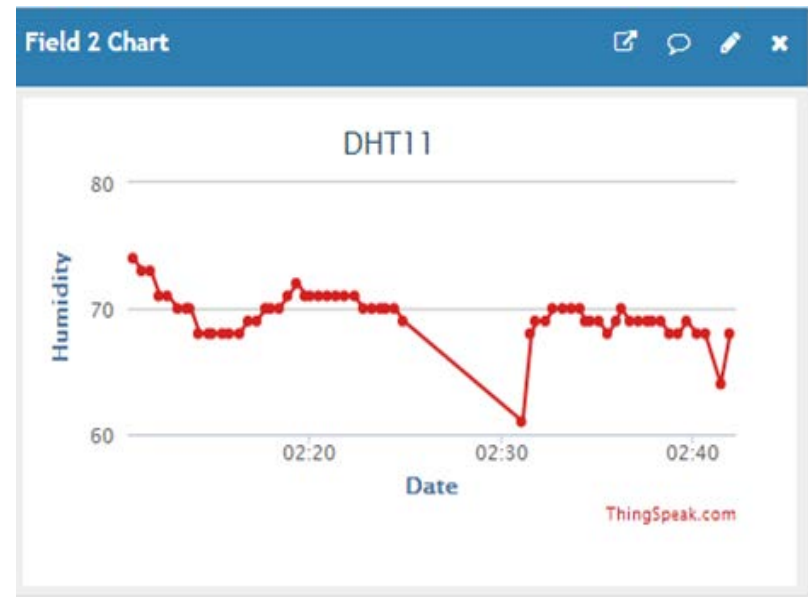

Fig. 8 Graphs drawn in Cloud server-Thingspeak

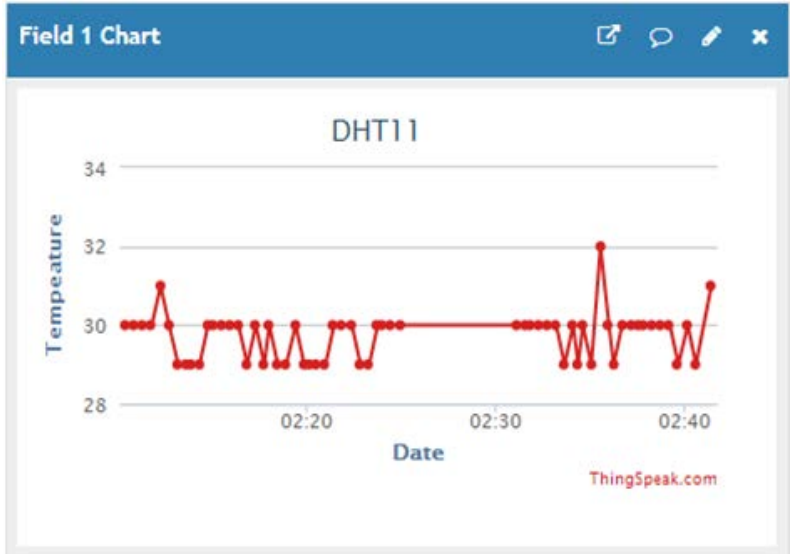

Fig. 9 Graphs drawn in Cloud server-Thingspeak 


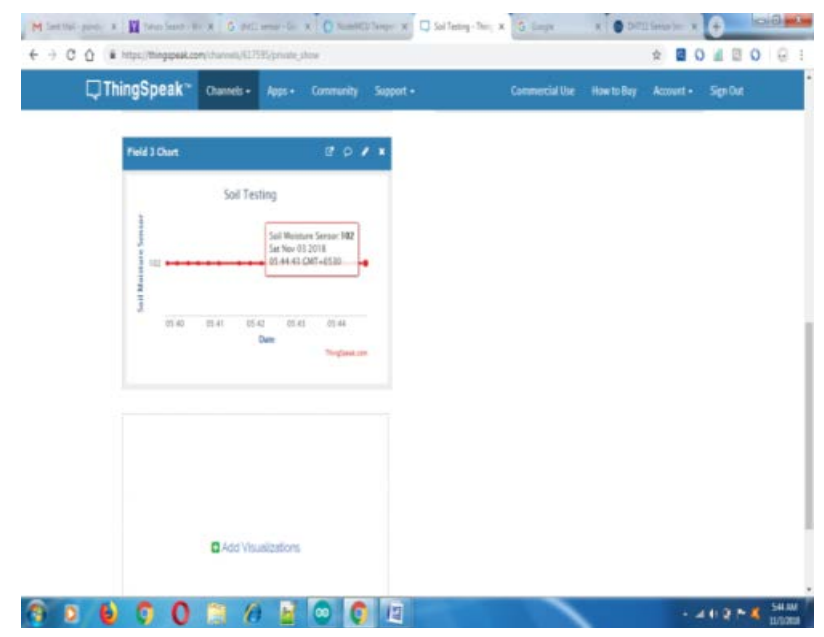

Fig. 10 Graphs drawn in Cloud server-Thingspeak

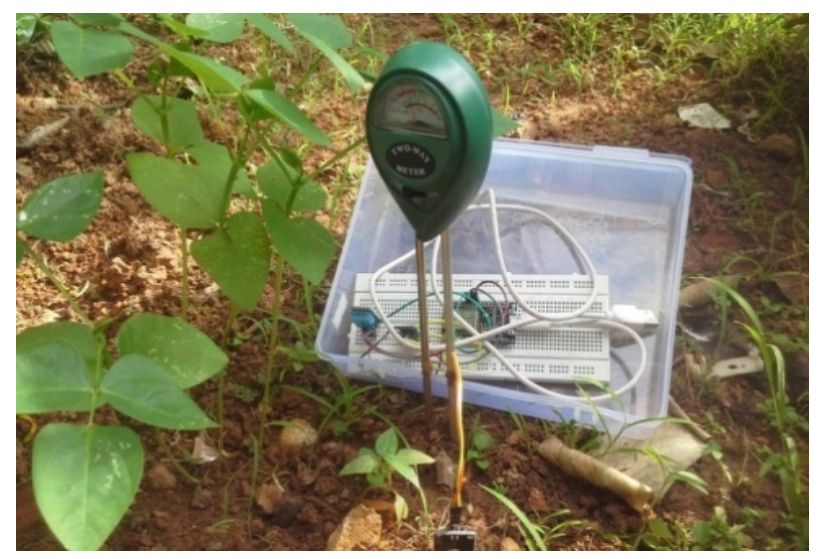

Fig. 11 Prototype of the System

\section{CONCLUSION}

In this "IoT Enabled Soil Testing” system, takes readings from soil moisture sensor and humidity sensor and store it in a cloud server and graph is drawn as per the variations in soil moisture, temperature and humidity level of the soil. The sensors and microcontroller are successfully interfaced with the cloud. The data is stored successfully and can be accessed remotely. All observations and experimental set up proves that this is a complete solution to test the soil health parameter. User can have access to the data and can know if there are any deviations with respect to $\mathrm{pH}$ value and soil moisture. Implementing this system will allow users like farmers to monitor and improve the productivity of the vegetables. The coding is done by using Arduino IDE, and for storing the sensor data in cloud server called Thingspeak.com by using WiFi. This work can be extended by adding advanced engineering technologies provided new approaches for soil testing with cost effective manner.

\section{REFERENCES}

[1] Anchit Garg, Priyamitra Munoth and Rohit Goyal, "Application of Soil Moisture Sensors in Agriculture: A Review”, Proc. Hydraulics, Vol. 21, pp. 1662-1672, 2016.

[2] [Online] Available at: http://soil quality.org.

[3] P. Sukumar, Dr. T. Kavitha, and V. Jashanavi, "Real Time soil Fertility Using IOT."Proc.NC's e-TIMES, 2018.

[4] J. Jayaprahas, S. Sivachandran, K. Navin, and K. Balakrishnan, "Real Time Embedded based Soil Analyzer”, Vol. 3,pp 5700-5703, 2014.

[5] Abdullah Ahmad, Ekram Khan, and WilliamIssac, "An Iot Based System For Remote Monitoring Of Soil Characteristics", Proc. InCITe, 2016.

[6] R. Sujatha, and R. Anitha Nithya, "A Survey on Soil Monitoring and Testing In Smart Farming Using IoT And Cloud Platform”, Vol. 7, No.pp. 55- 59, Nov. 2017.

[7] Komal Bodake, Rutuja Ghate, Himanshi Dashy, Piranha Judah and BalasahebTarle, "Soil based Fertilizer Recommendation System using Internet of Things", Vol. 1, No.1, pp.13-19, June 2018.

[8] A. NavyaSai Sri, and P. Ammi Reddy, "A Smart Framework for Agriculture Production Improvement using Web of Things", Vol. 50, No.5, pp.251-259 August 2017.

[9] M. Joshi, P.PS.S. Kanade, "Wireless Sensors and Agriculture Parameter Monitoring: Experimental Investigation”, Vol. 3, pp 06-13, May 2017.

[10] C. Kishore Kumar, and Veeramuth Venkatesh, "Cloud Based Soil Monitoring and Smart Irrigation System Using IoT and Precision Farming”, Vol. 119, pp. 2011-2020, 2018.

[11] Dr. N. Suma, Sandra Rhea Samson, S. Saranya, G. Shanmugapriya, and R. Subhashri, "IoT Based Smart Agriculture Monitoring System”, Vol. 5, pp177-181, Feb. 2017. 